\title{
Curriculum design for professional development in public health nutrition in Britain ${ }^{\dagger}$
}

\author{
Jacqueline Landman ${ }^{1, *}$, Judith Buttriss ${ }^{2}$ and Barrie Margetts ${ }^{3}$ \\ 1. Department of Dietetics and Nutrition, Queen Margaret College, Edinburgh EH 12 8TS, UK: \\ ${ }^{2}$ National Dairy Council, London WIM OAP, UK: and ${ }^{3}$ Institute of Human Nutrition, University of \\ Southampton, Southampton SO16 6YD, UK
}

\section{Submitted 5 November 1997: Accepted 20 December 1997}

\begin{abstract}
Objectives. To describe how the Nutrition Society developed public health nutrition as a profession between 1992 and 1997, and to analyse the influences propelling on this professionalization.

Design: Qualitative case study.

Setting: Britain.

Results: The Nutrition Society of Britain consulted with various stakeholders (such as dietitians, researchers, professionals and practitioners and educators from the UK, and latterly from mainland Europe) to build a consensus about the definition, roles and functions of public health nutritionists and the need for, and scope of, this new profession. Building on this consensus, the Society developed a curriculum in line with British national nutrition policy. Analysis shows that the design and philosophy of the curriculum is explicitly international and European in orientation, in keeping with the tradition of the discipline and the Society. The curriculum is designed in terms of specialist competencies in public health nutrition, defining competency so that registered public health nutritionists are advanced practitioners or leaders: this is in keeping with contemporary trends in professional education generally and as expressed by the UNU/IUNS and at Bellagio, in nutrition in particular.

Conclusions. Despite a unique relationship with British state and policy, this case of professionalization contributes to contemporary international inter- and intraprofessional debates about the nature of public health nutrition and is consistent with professional educational theory.
\end{abstract}

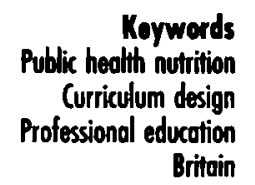

\section{Background}

The prevention of disease and promotion of health are widely acknowledged to require changes to the diet consumed in Europe ${ }^{1}$ and worldwide ${ }^{2}$. This has led many countries to formulate nutrition and food policies and to devise dietary guidelines or goals to improve the public's health. The European Union's (EU's) recent mandate for action (Article 129, Maastricht Treaty on European Union) is expected to generate demands for public health professionals within the EU, because effective food and nutrition policies require expertise in public health nutrition. Against this background, after a mere 5 years, a new professional qualification in public health nutrition was launched in London, on 1 December 1997. In order to discuss the issues in curriculum design which forms the subject for this paper, it is necessary to outline the chronology of the

\footnotetext{
${ }^{t} B a s e d$ on a paper presented at the Third Interdisciplinary conference
} in Berlin, hosted by AGEV/WZB October 1997. events that led to this momentous development. The Nutrition Society has published details about eligibility for this qualification both for individuals who wish to become registered and for higher educational institutions that wish to have their courses accredited ${ }^{3}$. Therefore the paper repeats only selected details necessary for clarity.

In 1992, for the first time since World War II, the government in the UK published a health policy which included explicit nutritional goals and targets, translated into dietary terms, called The Health of the Nation in England ${ }^{4}$, with comparable policies in other parts of the union, e.g. Scotland's Health: a Challenge to Us AlP. Expert committees were set up to initiate the programmes which would bring about the changes needed in the nation's diet. As a result, action plans were developed which describe the implementation of policy in a variety of programmes, for example, in England in Eat Well ${ }^{6}$ with a progress report in Eat Well II $^{7}$. 
As has long been the case, worldwide, formal nutrition education and training are significant aspects of nutrition policy ${ }^{8,9}$, at levels advanced enough for research and leadership ${ }^{10}$. The British Nutrition Task Force carried out its work by appointing specialist working groups. One such group concerned with nutrition education began a series of nationwide consultations brokered by the Department of Health in 1993. Thus agreement was reached about the need for all health professionals to be educated about the principles of nutrition. Furthermore, the Nutrition Task Force stated an intention to work with the universities and colleges to ensure that all the courses in nutrition (and in dietetics) 'equip their graduates to educate others, e.g. doctors, nurses, caterers and teachers' and to find means to offer courses of varying lengths to 'meet the needs of nutritionists working in industry' The Task Force also reported that, as part of its programme, it would continue to work with higher education and professional organizations to 'protect the professional standards of nutritionists' and 'to investigate forms of recognition for nutrition courses in UK universities and for individual graduates'. The Task Force would also 'work with UK higher education institutions to review the communications content of their courses to ensure that new graduates are equipped to meet the expected changes in their function arising from The Health of the Nation'. Subsequently, the Nutrition Task Force noted that these developments would help to dispel the confusion there seemed to be about and restore credibility to, nutrition ${ }^{7}$.

The Nutrition Task Force reported on the programme's progress in Eat Well $I I^{7}$. In education, a nutrition core curriculum for all health professionals had been 'enthusiastically adopted' by nurses, pharmacists and doctors ${ }^{11}$. Meanwhile the Nutrition Society, the largest learned organization dedicated to nutrition in Europe, had proceeded with consultation about and development of a process of accreditation in public health nutrition for courses and for individuals. The Nutrition Task Force noted that the Nutrition Society had agreed to the principle of accreditation in summer 1996 and is liaising with the British Dietetic Association so that a workable and acceptable method is designed'.

To put these developments in context, in 1989, a register in nutrition had been established, maintained by the Institute of Biology, which is a chartered institution in the terms of the European Directive 89/ 48/EEC on the Mutual Recognition of Professions ${ }^{12,13}$. The existence of this register shows that the process of professionalization in nutrition was already underway. Spurred by national nutrition policy, agreement was reached about the need to develop a more specialist profession in public health nutrition, under the auspices of the Nutrition Society. This was a new departure for that august institution ${ }^{14}$.

\section{The development of public health nutrition}

In 1995, the Nutrition Society appointed a Public Health Nutrition Development Group. At any one time, this group comprised five members, drawn from public health nutrition research, higher education, industry and community dietetics. The membership of this small group changed but retained this wide range of expertise. From July 1996, the Public Health Nutrition Development Group included a member from mainland Europe and the International Union of Nutrition Sciences (IUNS) Committee on Public Health Nutrition. This reflects the facts that the Nutrition Society has many members who reside outside Britain ${ }^{15}$ and has a long-standing commitment to European and international nutrition institutions. It also reflected the obligation that members of the EU have to recognize each others' qualifications, under the global commitment to encourage free trade and movement of labour, in terms of General Agreement on Tariffs and Trade (GATT). In Europe, Jacques Delors, then President of the European Commission, stated this committment as the 'right to exercise one's occupational and professional activity anywhere in Europe ${ }^{16}$.

In summary, since its inception in 1995, the Public Health Nutrition Development Group has vigorously canvassed the views of a wide range of key stakeholders in public health nutrition, in order that there could be a broad basis for any consensus reached. By widening participation in the decision-making process, it was hoped to foster a sense of commitment born of a perception of ownership of the process. The Public Health Nutrition Development Group notably consulted with dietitians who could feel threatened because dietitians have been working in the community to prevent disease and promote nutrition since $1974^{17}$. Detailed consultation led to perceived overlap in roles and functions between public health nutritionists and dietitians (as shown in Fig. 1) but with the possibility of drawing a boundary between the two.

Thus it is generally agreed that public health nutritionists do not provide counselling for individuals. Less clearly, but arguably, it seemed that few dietitians apply epidemiology, use statistics or work at the population level in the ways that are essential to set regional and district targets consistent with the national goals for nutrition. British community dietitians have stated that their non-clinical technical functions could be called 'health promotion or nutrition education'18. British community dietitians have also stated their perceived need for more expertise in research and evaluation and for postgraduate courses in community nutrition/dietetics, separately, or within public health. 


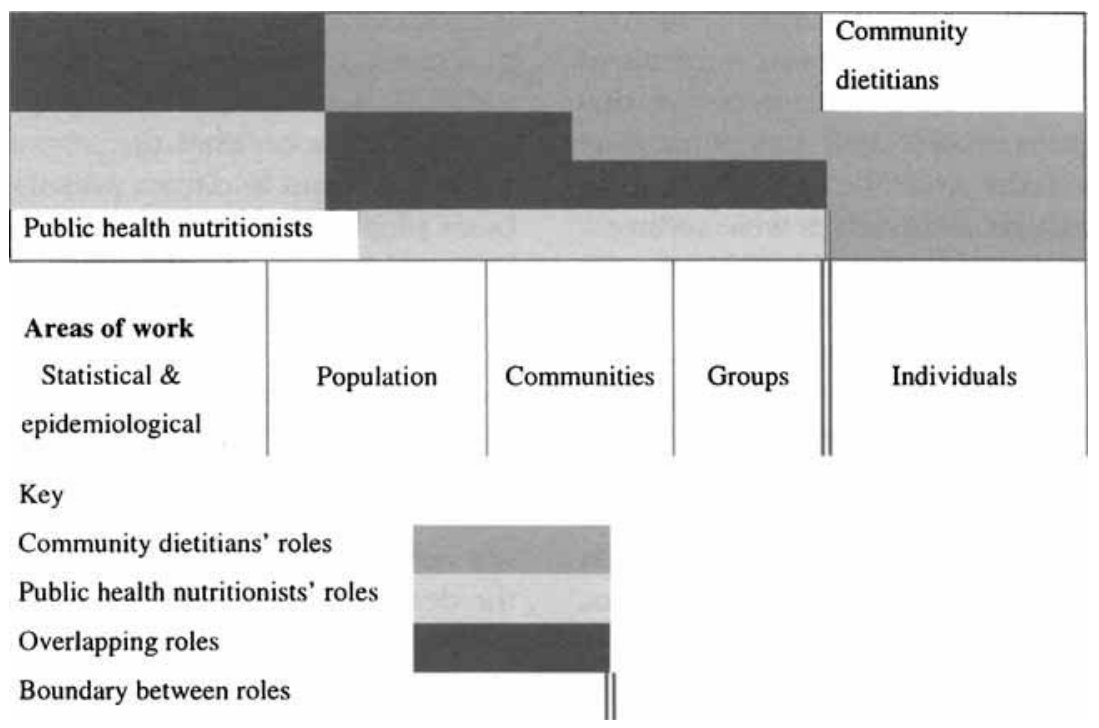

Fig. 1 The complementary roles of public health nutritionists and community dietitians: overlap and uniqueness. Adapted from Public Health Nutrition, A consultation paper prepared on behalf of the Nutrition Society (1995) and Dietitians in the community: opportunities for the future British Dietetic Association (n.d.)

Thus there is more overlap than distinction between the functions of public health nutritionists and the functions of community dietitians in the UK. Moreover, in Britain, public health nutritionists can be registered dietitians and dietitians can be public health nutritionists, as also occurs in Australia, the Caribbean and the USA.

In the USA, for many years, public health nutritionists have combined the management of nutrition services with therapeutic dietetics ${ }^{19,20}$. In 1988, Kaufman and Lee reported that fewer managers stipulated that public health nutritionists must hold postgraduate qualifications in nutrition or public health nutrition, than 2 years previously. Kaufman and $\operatorname{Le}^{20}$ concluded that there was a need for more population-based assessment of nutritional needs, stronger advocacy of nutrition policies and implementation of data systems, so that public health nutritionists could raise the profile of primary preventative nutrition, in line with public interest and national goals. Thus, Kaufman and $\mathrm{Lee}^{20}$ recommended a conception of public health nutrition that is closer to that envisaged by the Nutrition Society ${ }^{3}$ and Hughes and Somerset ${ }^{21}$.

On behalf of the Nutrition Society, the Public Health Development Group established a definition of public health nutrition:

Public Health Nutrition focuses on the promotion of good health through nutrition and the primary prevention of diet-related illness in the population. The emphasis is on the maintenance of wellness in the whole population

Nutrition Society ${ }^{3}$

The art and science of promoting population health status via sustainable and equitable improvements in the food and nutrition systems. Based upon public health principles it is a set of comprehensive and collaborative activities, ecological in perspective and inter-sectoral in scope - including environmental, educational, economic, technical and legislative measures

$$
\text { Hughes \& Somerset }{ }^{21}
$$

In this context, it was possible to identify the likely organizations and employment opportunities for public health nutritionists. Leading on from this it was possible to identify an agreed list of competences essential for a public health nutritionist to have and the additional specialist knowledge required to underpin these.

Armed with agreement on these matters, the Nutrition Society convened a workshop, again in conjunction with the Department of Health, in April 1996. In preparation for this meeting, the Public Health Nutrition Development Group had undertaken an audit of courses offered in nutrition in the UK to find out which elements of the proposed core curriculum in public health nutrition were already taught. Participants in the workshop were representatives of higher education institutions offering courses in nutrition and other important stakeholders from health promotion/health education, dietetics and industry, but excluding employers' representatives. As a result, it was clear that there was agreement about the principle of accrediting courses and individuals, with a need to work on how to verify or validate these processes. The report of this meeting led to agreement on a proposal for procedures for registration and accreditation, as the Task Force on Nutrition reported in 1996, thereby 
fulfilling one of the objectives that the Task Force had set in 1994. Following minor changes as a result of further consultation with colleges and universities that confer nutrition degrees in the UK, the curriculum reached its present form and the procedures for accreditation of individuals and courses were refined ${ }^{3}$.

It is noteworthy that the curriculum for public health nutrition is embedded in the discourse of competence. This is because the Nutrition Society adopted the approach to curriculum design used by established professions, i.e. consultation with practitioners (and employers) in order to achieve consensus about the nature of the scope of the professional occupation, upon which to base the curriculum. Competence in public health nutrition was defined in broad terms, primarily in terms of cognitive abilities ${ }^{3}$. The document Register in Public Health Nutrition: Pbilosopby and How to Apply, however, makes explicit the general requirement for competence in communication and in interpersonal skills, such as working in a team, and organizational ability, which have become known as 'transferable' or 'life' skills. Similar value has been placed upon such interpersonal and leadership skills by the IUNS/United Nations University (UNU) ${ }^{10}$, and by research among professionals and practitioners in public health nutrition in the USA ${ }^{22}$, Central America ${ }^{23}$, the Caribbean ${ }^{24}$ and in Australia. In this regard, public health nutrition in Britain is part of the movement towards relevance in higher education in the $\mathrm{UK}^{25}$, as has already occurred in the USA ${ }^{26}$ and in Austra$\mathrm{lia}^{27,28,29}$. Statements about the need for these 'transferable skills' represent a fundamental shift from the discipline-based view expressed in Review of Courses in Nutrition ${ }^{12}$.

The curriculum in public health nutrition extends the scope of nutrition beyond its disciplinary roots in the biomedical sciences, by including three interdisciplinary topics:

- 'the psychological, social and cultural factors which influence food and dietary choices and how to effect change through modification of these';

- 'principles and key components of health education and health promotion policies and programmes',

- 'sociology and politics of institutions, stakeholders, agents and agencies in national and global food and public health systems, sustainability and equity in Public Health Nutrition programmes'.

Competence is needed in these topics in order to cooperate with specialists in the social sciences and in health education and health promotion, in the prosecution of public health nutrition, rather than expecting specialist expertise in each of these disciplines. Thus the vision of interprofessional collaboration defined the need for professional public health nutritionists to develop, to high levels, inter- personal skills which will enable them to work in teams and manage time, staff and other resources.

While development of the curriculum included a consideration of what the term 'competence' means, the main focus of debate was the unique disciplinary basis of public health nutrition for competence. This task was never constructed in terms of devising competency statements within clearly differentiated domains of the kinds that characterize dietetics in Australia $^{27,28}$ and the $\mathrm{USA}^{26}$, as it took a less functionalist approach. The design of the curriculum for public health nutrition eschews statements of narrow behavioural objectives also called 'skills'. By not defining 'skills' minutely as behavioural objectives, the design of the curriculum for public health nutrition in Britain avoids a subject of continued controversy in professional educational circles ${ }^{29-31}$. Albeit tacitly, the Nutrition Society has quite deliberately ensured that the philosophy for public health nutrition reflects commitment to academic freedom, with more scope for a liberal education than training simply in skills allows.

Although it does not explicitly comment on the general distinction between 'novice' and 'expert' or 'advanced level' practitioners, the curriculum clearly defines the public health nutritionist as a specialist with far more knowledge and skills in nutrition than health professionals generally have (for example, greater than the levels prescribed by the Department of Health in Nutrition, Core Curriculum for the Education of Health Professionals, published in 1994) ${ }^{11}$. Indeed the curriculum for public health nutrition stipulates explicitly that professional public health nutritionists should have the competence to teach other health professionals and hence meets the policy objective set by the Nutrition Task Force ${ }^{6}$. Moreover, one of the Society's criteria for registering a public health nutritionist, is that (s)he should have at least 3 years relevant recent professional experience, which could include advanced, postgraduate education in research in public health nutrition, i.e. mid-level planners, researchers and teachers in IUNS/UNU terms.

In terms of the debate about the nature of professional education, for advanced level functioning or leadership, the Nutrition Society explicitly adopts the view that professionalism is not merely the capacity to replicate the same performance (i.e. training). This is the significance of the expectation that public health nutrition courses will educate for high-level cognitive abilities 'knowledge and understanding, analysis, synthesis, creativity and evaluation', in Register in Public Health Nutrition: Philosophy and How to $A p p l y^{3}$. In keeping with contemporary approaches ${ }^{30}$ to curriculum design, it was important to define levels of competence in terms based on transparency, equity and flexibility of access and recognition of the diverse models of nutrition course curricula. In order to assure 
rigour in educational quality, the Public Health Nutrition Development Group produced a document called Specifying Levels of Learning Outcome in Public Health Nutrition. This includes descriptions of levels of learning outcome for each prescribed topic and notes that tutors should encourage independence and creativity by placing their students in complex and varied situations without close supervision. The purpose of Specifying Levels of Learning Outcome in Public Health Nutrition is to guide the Society when it assesses the suitability of courses for accreditation and to help academics to shape their curricula to meet the requirements for accreditation. The guidelines were agreed in consultation with representatives of the majority of courses in the UK in 1997.

In Britain, the number of new dietitians is determined by the number of professional training places, an intractable constraint at present, which presents a stumbling block for planning specialist human resources in nutrition, except in public health nutrition. However, the design of the public health nutrition curriculum extends beyond the narrow remit of human resource planning in health, in that it explicitly encompasses the basic causes of nutritional status, using a systems approach. Thus it has at its heart equity, sustainability and participation. The conceptual framework that links these basic and fundamental issues is key to the discourse of international nutrition for development that guides the multilateral technical agencies. The conceptual framework was firstly expressed by the United Nations International Children's Emergency Fund (UNICEF) (for example, 1990) and was adopted at the International Conference on Nutrition $^{32}$. Therefore the design of this curriculum may be seen to respond positively to the criticism made by Berg in $1991^{33}$ that nutrition could be 'sliding towards nutrition malpractice', in that it is framed in the spirit of the international consensus on nutrition education and training expressed at the Bellagio Conference and a subsequent report on progress in educating a new kind of professional ${ }^{34,35}$. The central point of agreement is about producing a nutrition professional who must be able to perform creatively. British public health nutrition expects this from autonomous trainees but does not stipulate that education and training occur in the context of a development project as post-Bellagio training envisages.

Autonomy from, but close relationship with, the State is one of the features of professions said to be uniquely British ${ }^{36,37}$. In the UK, the accreditation of individuals and courses is usually undertaken by a voluntary or chartered professional organization, to which the majority or all the profession belongs. Or there is a body that exercises statutory powers, with membership controlled by law but mainly representative of the profession. Although it lacks the imprimatur of the law or a charter, the Nutrition Society is the premier learned society for nutrition in the UK, without being narrowly national in that $40 \%$ of its members reside in mainland Europe or abroad. The structure and functioning of the Society reflect the international character of the discipline. Thus competence in public health nutrition is explicitly defined in European not merely British terms and recognizes the value of knowledge about other places or the transferability of precepts. While a voluntary system of registration will lack the force of the law to protect title it permits the flexibility for developments beyond national legal boundaries. The unique character of the relationship between government and the professions in the UK means that this case-study is not generalizable to countries without this condition.

Having stated that this is a case-study, necessarily few claims are made for the applicability of the process, given the specificity to the context and conjuncture of the issues and debates that influenced the design of the curriculum in British public health nutrition. It is clear from the documentary evidence that the curriculum design process was necessarily bounded to residents of the UK. This spatial location of the design process resulted partly from the dictates of policy. Importantly and pragmatically, this was also a function of the logistical difficulties of consulting outside the country, in the short term. The Public Health Nutrition Development Group considered the paper by Hughes and Somerset ${ }^{21}$ and adopted their definition of public health nutrition, a substantive contribution to the philosophy of public health nutrition in Britain. There is less clear-cut evidence that other views or debates influenced the design of public health nutrition in Britain. The Nutrition Society's papers do not enter the debate about 'public nutrition' 38,39 . There is, however, agreement about the need to make more explicit a broad vision, interdisciplinary character and commitment to popular service: values that are included in the definition of public health nutrition adopted for Britain. The Nutrition Society chose the term 'public health' rather than 'community' (or 'population' ${ }^{40}$ ) recognizing the philosophical basis for, societal levels of and primary institutional frameworks for, public health nutrition in Britain. There is, however, a need for further debate about how to combine - some would say reconcile - the epistemologies of quantitative nutrition science with qualitative profession-related social sciences that will underpin the leadership and will deliver the holisitic, problem-solving competence that British public health nutrition and 'public nutrition' aspire towards. The Nutrition Society has not yet formally debated the values and theoretical issues that inform the problem-solving model for advanced education proposed by Pelletier ${ }^{41}$. Newly registered 
public health nutritionists in Britain will be debating values and ethics for practice, in a European context, as practitioners, researchers and educators build partnerships with purchasers of public health nutrition as a public good. Thus debates about philosophy, epistemology and values in public health nutrition must continue at local and international levels, as the profession meets the practical challenges of public health nutrition, and as is intrinsic to a 'self-evolving system' that distinguishes a profession ${ }^{42}$.

\section{References}

1 James WPT. Healtby Nutrition. Copenhagen: European Regional Office of the World Health Organization, 1988.

2 WHO. Diet and the Prevention of Chronic Diseases. Geneva: World Health Organization, 1990.

3 Nutrition Society. Register in Public Health Nutrition: Philosophy and How to Apply. London: Nutrition Society, 1997.

4 Department of Health. The Health of the Nation. A Strategy for Health in England. London: HMSO, 1992.

5 Scottish Office Department of Health. Scotland's Health, a Challenge to Us All. Edinburgh: HMSO, 1992.

6 Department of Health. Eat Well. An Action Plan from the Nutrition Task Force to Achieve the Health of the Nation Tangets on Diet and Nutrition. Wetherby: Department of Health, 1994.

7 Department of Health. Eat Well II. A Progress Report from the Nutrition Task Force on the Action Plan to Achieve the Health of the Nation Targets on Diet and Nutrition. Wetherby: Department of Health, 1996.

8 Beeuwkes A. Nutrition education. World Rev. Nutr. Diet 1965; 5: 1-20.

9 Fidanza F, Jelliffe EFP, Babchi K, et al. Nutrition education and training for health science professions. World Rev. Nutr. Diet. 1981; 38: 154-221.

10 UNU/IUNS Executive Summary. Institution-building for Research and Advanced Training. Report of a workshop held by UNU and IUNS in Manila. Food Nutr. Bull. 1997; 18: 103-9.

11 Department of Health. Nutrition. Core Curriculum for Nutrition in the Education of Health Professionals. Wetherby: Department of Health, 1994.

12 Institute of Biology. Training of Nutritionists. A report for the Nutrition Society by the Institute of Biology's Review Group on the Training of Nutritionists. London: Institute of Biology, 1991.

13 Institute of Biology. Register of Accredited Nutritionists. Sponsored by the Institute of Biology, the Nutrition Society and the Institute of Food Science and Technology. London: Institute of Biology, third edition, 1995.

14 Webster J. Tribes and professions (editorial) Br. J. Nutr. 1994; 71: $799-800$.

15 Jackson A. Does the Nutrition Society serve the needs of its overseas members? Proc. Nutr. Soc. 1991; 50: 1-7.

16 Department for Trade and Industry. The Single Market. Europe Open for Business. London: Department for Trade and Industry, and Central Office of Information.

17 Bateman C. The British Dietetic Association, 1936-1986. Birmingham: British Dietetic Association, 1986.

18 British Dietetic Association. Dietitians in the Community: Opportunities for the Future. Birmingham, British Dietetic Association, no date.

19 American Public Health Association. Educational qualifications of nutritionists in health agencies. Am.J. Publ. Health 1962; 52: 116-21.
20 Kaufman M, Lee S. Nutrition services in state and local public health agencies. How do we measure up in 1987 ? $\mathrm{J} . \mathrm{Am}$. Diet. Assoc. 1988; 88: 1576-80.

21 Hughes R, Somerset S. Definitions and conceptual frameworks for public health nutrition and community nutrition: a discussion paper. Aust. J. Nutr. Diet. 1997; 54: 40-5

22 Olmstead-Schafer M, Story M, Haughton B. Future training needs in public health nutrition: results of a national Delphi survey. J. Am. Diet. Assoc. 1996; 96: 282-3.

23 Rogers B, Schlossman N. 'Public nutrition': the need for cross-disciplinary breadth in the education of applied nutrition professionals. Food Nutr. Bull. 1997; 18: 120-33.

24 Corby L. Assessment of community development and leadership skills required by Caribbean nutritionists and dietitians: research and international collaboration in action. J. Nutr. Educ. 1997; 29: 250-7.

25 Burrage $M$. Routine and discreet relationships: professional accreditation and the state in Britain. In: $T$. Becher, ed. Governments and Professional Education. Buckingham and Bristol: Society for Research in Higher Education and Open University Press, 1994.

26 O'Sullivan-Maillet J. The competencies continuum in nutrition. Nutrition 1997; 13: 840-1.

27 Ash S, Capra S, Cumming F, Gibbons K, Roberts N, Tapsell L. Viewpoint article: definitions and conceptual framework for public health and community nutrition (letter). Aust.J. Nutr. Diet. 1997; 54: 152-3.

28 Gonczi A. Competency-based assessment in the professions in Australia. Assess. Educ. 1994; 1: 27-44.

29 Hager P, Gonczi A. Competency-based standards: a boon for continuing professional education? Stud. Continuing Educ. 1991; 13: 24-41

30 Bridges D. Competence-based education and training progress or villainy? J. Phil. Educ. 1996; 30: 361-75.

31 Ashworth PD, Saxton J. On 'competence'. J. Further Higher Educ. 1990; 14: 3-25.

32 FAO/WHO. Nutrition and Development - a Global Assessment. International Conference on Nutrition. Geneva: WHO, 1992.

33 Berg A. Sliding towards nutrition malpractice: time to malpractice and redeploy. Am. J. Clin. Nutr. 1993; 57: 3-7.

$34 \mathrm{ACC} / \mathrm{SCN}$. Training and Research Needs in Nutrition. Summary of Proceedings of a Bellagio Conference on Addressing the 'How' Questions in Nutrition: Unmet Training and Research Needs. Geneva: ACC/SCN, 1995.

35 Bellagio Conference. Addressing the 'How' Questions in Nutrition: Unmet Training and Research Needs. Geneva: ACC/SCN, 1995.

36 Siegrist $\mathbf{H}$. The professions, state and government in theory and history. In T. Becher, ed. Governments and Professional Education. Buckingham and Bristol: Society for Research in Higher Education and Open University Press, 1994.

37 Johnson $T$. The state and the professions: peculiarities of the British. In Giddens A, McKenzie G, eds. Social Class and the Division of Labour. Cambridge: Cambridge University Press, 1982.

38 Mason J, Habicht JP, Greaves JP, et al. Public nutrition (letter). Am. J. Clin. Nutr. 1996; 63: 399-400.

39 Eide WB, Oshaug, A. Community, public and global nutrition (letter). Am. J. Clin. Nutr. 1997; 66: 197-8.

40 Labonte $R$. The population health/health promotion debate in Canada: the politics of explanation, economics and action. Critical Publ. Health 1997; 7: 7-25.

41 Pelletier D. Advanced training in food and nutrition; disciplinary, interdisciplinary and problem oriented approaches. Food Nutr. Bull. 1997; 18: 134-45.

42 Houle C. Continuing Learning in the Professions. San Francisco: Jossey-Bass, 1980. 